\title{
0 trabalho informal na indústria de calçados: experiências e percepções dos agentes ${ }^{I}$
}

Felipe Rangel ${ }^{*}$

\begin{abstract}
Resumo: Neste texto pretendemos analisar o trabalho informal no setor calçadista no Estado de São Paulo e seu crescimento a partir dos processos de deslocamento industrial e generalização da terceirização. Buscamos, também, verificar a influência dos discursos sobre empreendedorismo na valorização do trabalho autônomo. Para tanto, assumimos como recorte o estudo de unidades produtivas informais (bancas) em três polos produtivos do Estado marcados por grande informalidade: Franca, Jaú e Birigui. A partir de estudos de caso, buscamos conhecer as diversas condições de realização do trabalho informal, dedicando especial atenção às manifestações do discurso empreendedor por parte dos trabalhadores. Se, por vezes, o trabalho autônomo informal nas bancas traveste-se de empreendedorismo, dando um verniz modernizador a uma situação de precariedade não mais vista como transitória, mas constituinte das novas e flexíveis formas de organização do trabalho, muitos são os casos em que a ocupação é percebida na sua evidente precariedade, tratando-se de uma espécie de "empreendedorismo por necessidade".
\end{abstract}

Palavras-chave: informalidade, empreendedorismo, terceirização, indústria de calçados.

\section{Introdução}

A subcontratação de oficinas e trabalhadores para a execução de etapas da confecção do calçado que tendem a gerar "gargalos" na produção é uma prática historicamente utilizada pelas indústrias. Em meados da década de 1970, já era comum a subcontratação das chamadas "bancas" (oficinas terceirizadas que confeccionam partes do calçado), muitas delas instaladas no domicílio dos trabalhadores. Navarro (2006), ao realizar um estudo sobre a indústria de Franca, destaca a participação majoritária das mulheres no trabalho informal nesse período, especialmente na atividade de costura manual, principal tarefa externalizada na época. É preciso salientar que essa externalização tradicionalmente se dava por contingência, quando o volume da produção estava além da capacidade produtiva das fábricas.

Na década de 1980, contexto em que os impactos do processo global de reestruturação produtiva começaram a ser percebidos no Brasil, a prática de externaliza-

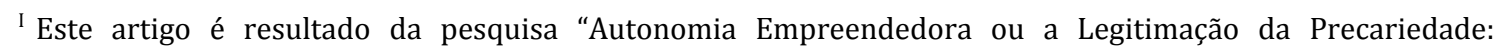
Trabalhadores Domiciliares na Indústria de Calçados” - Estudo Apoiado pela Fapesp.

* Graduando em Ciências Sociais - UFSCar.
} 
ção perde gradualmente seu caráter contingencial e passa a responder, primordialmente, ao ideal da redução de custos, em harmonia com o paradigma da "empresa enxuta". Além de reduzir as despesas com mão de obra, a subcontratação das bancas se mostrou uma prática extremamente vantajosa para as empresas por possibilitar maior flexibilização do processo produtivo, permitindo um controle mais eficiente da produção perante a sazonalidade característica da demanda no setor de calçados.

Nesse novo contexto, caracterizado pela busca constante por formas de flexibilização, a prática de subcontratação ganhou aspectos modernos e positivos sob o termo "terceirização", sendo interpretada como simples e imprescindível estratégia empresarial, condição para a manutenção das empresas na ordem competitiva. Como sugere Druck (2011), a terceirização encontrou sua justificação na medida em que foi legitimada e utilizada de forma epidêmica como "ferramenta" ou "estratégia" de sobrevivência empresarial numa conjuntura de crise e instabilidade, marcada pela reestruturação da indústria nacional e inserção desta na lógica competitiva global. No que se refere à cadeia produtiva, as relações entre empresas e trabalhadores tendem a se converterem em relações interempresariais assimétricas, nas quais a empresa contratante determina os padrões de produção, prazos e preços. Esse processo implica numa multiplicidade de relações de trabalho que tendem a assumir contornos cada vez mais precários, conforme as empresas e trabalhadores terceirizados se situem em posições mais periféricas dentro da cadeia produtiva (LIMA, 2010). Com efeito, esse padrão de terceirização adquire contornos perversos na medida em que a busca pela redução de custos se objetiva através da exploração do trabalho precário.

Ao longo da década de 1990, os principais polos produtores de calçados no Brasil, com destaque para a região do Vale dos Sinos e Franca, assistiram à redução do número de empregos formais na indústria local. 0 aumento da terceirização é uma das causas desse processo, visto que eliminou milhares de postos de trabalho e conduziu grande contingente de trabalhadores à condição de prestadores de serviço, muitos atuando na informalidade. Por outro lado, ao refletir sobre a redução dos empregos nesses polos, deve-se considerar também o impacto do processo de deslocamento espacial das indústrias, que incorporou na configuração industrial do país, áreas antes marginalizadas. Como forma de enfrentar a crise provocada pela abertura econômica dos anos 1990, muitas indústrias transferiram unidades para estados do Nordeste brasileiro, que se mostraram atrativos para as empresas 
no contexto da "guerra fiscal" promovida por prefeituras e governos estaduais. De acordo com Lima (2002), além de disponibilizar mão de obra abundante, barata e desorganizada, diversos governos do Nordeste passaram a oferecer também renúncia fiscal, infraestrutura, treinamento de trabalhadores e, até mesmo, organização de cooperativas para terceirização. A intenção era atrair toda a cadeia produtiva de calçados, não apenas fábricas avulsas. 0 emprego gerado nessa região já nasce precário e convivendo com a instabilidade provocada pela mobilidade constante do capital, que só permanece em um determinado local enquanto os incentivos estiverem em vigência. No entanto, a precarização deve ser considerada em termos comparativos, numa região onde os trabalhadores pouco conheciam a atividade industrial ou relações de assalariamento formal, até mesmo os empregos precários criados pela desterritorialização industrial aparecem travestidos de um aspecto positivo.

Nas regiões de origem dessas indústrias, os trabalhadores tiveram que conviver com o crescimento do desemprego e, consequentemente, da informalidade. Multiplicaram-se as bancas de calçados pelos bairros periféricos das cidades, muitas delas organizadas por ex-funcionários das fábricas que se tornaram trabalhadores terceirizados. Esse movimento contou com forte apoio empresarial, visto que fábricas chegavam a emprestar máquinas para funcionários que se dispusessem a trabalhar como prestadores de serviço, montando o "próprio negócio" (NAVARRo, 2006). Nessa nova conjuntura, o trabalho domiciliar deixou de ser uma ocupação quase exclusivamente feminina e passou a significar uma alternativa ao desemprego para os trabalhadores em geral.

A consolidação do trabalho informal como constituinte das novas configurações do processo produtivo, assim como sua legitimação como alternativa de inserção no mercado de trabalho em um contexto de crise do assalariamento, se deu também pela concepção do trabalho na informalidade como um meio de canalização do espírito empreendedor dos trabalhadores. No contexto da hegemonia neoliberal, a informalidade, antes vista como sintoma do subdesenvolvimento, ganhou contornos mais positivos, sendo ressignificada sob a noção de empreendedorismo. 0 discurso do empreendedorismo passou a veicular a imagem do novo trabalhador como um sujeito capaz de ser flexível perante as adversidades do mercado, criativo e que está disposto a assumir os riscos do investimento no próprio negócio. Quanto mais próximo o trabalhador estiver da figura do "empreendedor de si mesmo", mais estará assegurada sua permanência no mercado de trabalho, sua empregabilidade. A noção 
de empreendedorismo assumiu feições de ideologia e passou a influenciar interpretações sobre o mundo do trabalho com forte viés individualista, dando maior destaque às qualidades individuais em detrimento das relações sociais (MELo, 2008). Pode-se dizer que o discurso empresarial, veiculado pela mídia e por instituições como o SEBRAE, tem contribuído para a adesão voluntária dos indivíduos à proposta da produção flexível, assim como para a construção de um ethos adequado a essa nova fase do capitalismo (MELo, 2008).

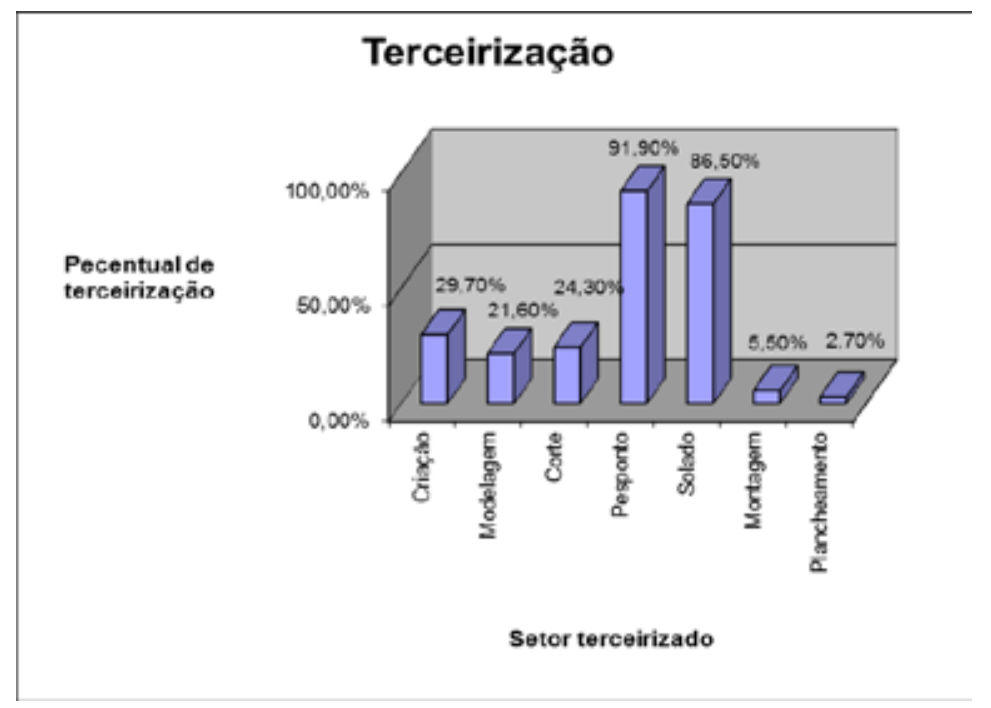

Fonte: SEBRAE. "Estudo da Atividade Empresarial: Setor Calçadista - Fabricação de Calçados Femininos - JAÚ - SP", 2003.

Tendo em vista este quadro, procuramos perceber em que medida se pode dizer que há a incorporação do discurso empreendedor pelos trabalhadores informais na indústria de calçados, bem como compreender a visão que esses agentes têm sobre sua própria situação de "pequeno empreendedor" e que, ao mesmo tempo, está à mercê da imposição da demanda das fábricas e da instabilidade do setor de calçados, numa condição de autonomia e submissão. A primeira etapa da pesquisa foi dedicada ao levantamento de dados acerca da situação da indústria de calçados no Estado de São Paulo, caracterizando os três polos produtivos selecionados: Franca, Jaú e Birigui. Foram coletados dados junto ao Ministério do Trabalho e Emprego (MTE), Associação Brasileira das Indústrias de Calçados (ABICALÇADOS) e Sindicatos das Indústrias dos três municípios estudados. Também foi realizado um levantamento bibliográfico sobre mercado de trabalho, informalidade e trabalho domiciliar no setor calçadista. Em seguida, realizamos visitas a unidades produtivas em todos 
os polos. No total, foram visitadas 15 bancas e 4 fábricas de calçados, onde foram entrevistados trabalhadores e proprietários.

\section{As faces da terceirização na indústria de calçados}

Ao longo desta pesquisa, foram verificadas algumas das configurações assumidas pela terceirização na indústria calçadista. Como destaca Almeida (2010), a terceirização na indústria de calçados está longe de ser uma prática homogênea. As formas de subcontratação se dão através de uma diversidade de acordos, contratuais ou não. Primeiramente, pode-se partir da terceirização envolvendo duas empresas, a contratante e uma prestadora de serviços. Quando formalizada, o trabalho na banca terceirizada tende a ser executado em condições semelhantes ao realizado no interior da fábrica. Os trabalhadores, geralmente, são registrados e, assim, estão cobertos pelos direitos vinculados ao assalariamento formal. A jornada de trabalho segue a determinação legal, muito embora ocorra, frequentemente, a realização de horas extras (chamadas de "cerão") nos períodos de maior produtividade ou atraso nas encomendas, situação que também se verifica no cotidiano das fábricas.

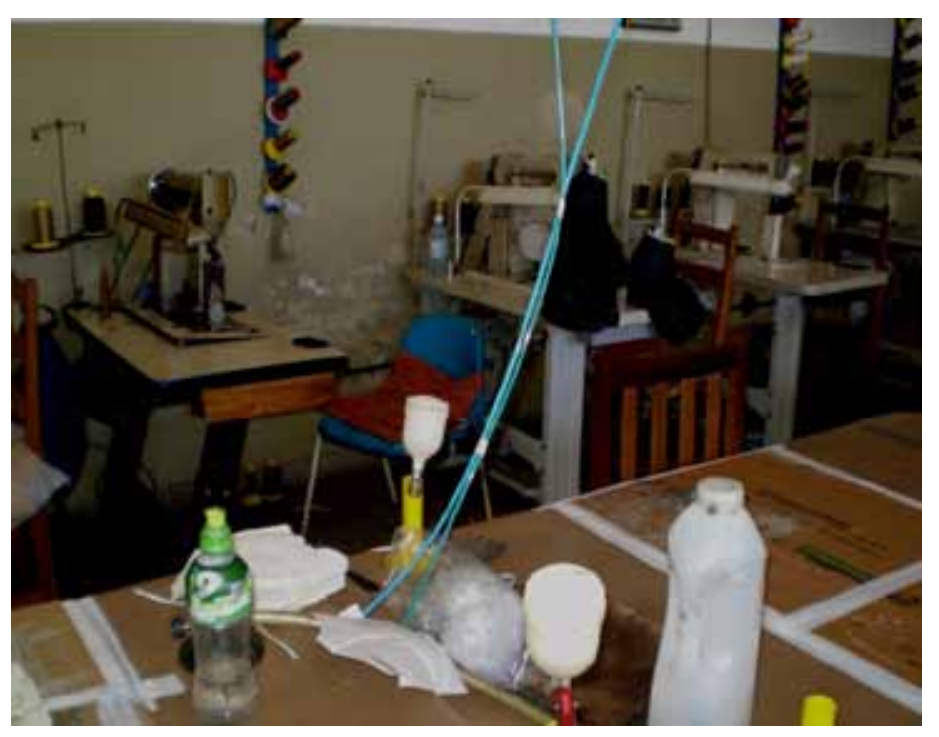

Banca de pesponto formalizada

Contudo, quando a oficina terceirizada não é regularizada, o trabalho tende a ser executado em condições acentuadamente mais precárias, em ambientes inadequados para a atividade (pouca iluminação, forte cheiro de cola em consequência da fraca ventilação, máquinas em mal estado). Muitas vezes, o responsável pelo 
empreendimento paga aos outros trabalhadores uma remuneração acima do piso da categoria, para compensar a falta de registro na carteira de trabalho. A ausência de registro deixa os trabalhadores em grave situação de vulnerabilidade, principalmente quando levamos em consideração a sazonalidade da produção de calçados. No final do ano, a produção tende a diminuir radicalmente, o que conduz à demissão de muitos trabalhadores. Os que trabalham registrados recebem o seguro-desemprego até que chegue o período de recontratações, que se arrasta gradualmente até o meio do ano. Já os trabalhadores informais ficam desempregados e sem poder contar com qualquer benefício.

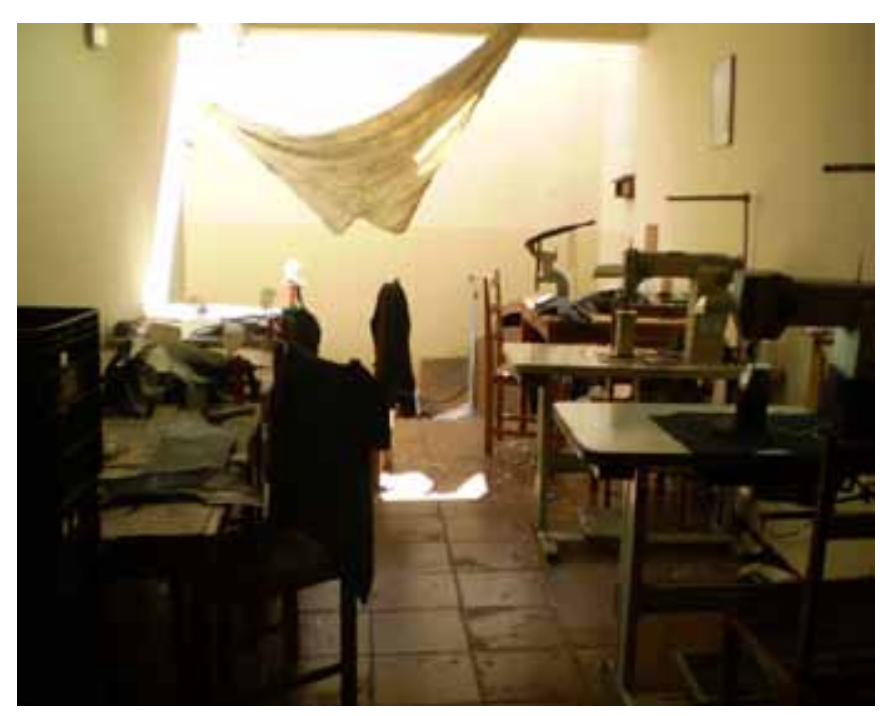

Banca de pesponto domiciliar

Entre as formas de subcontratação do trabalho terceirizado, o trabalho domiciliar merece grande destaque. As bancas domiciliares são instaladas em garagens, fundos de quintal, galpões de madeira, ou mesmo nas salas e cozinhas das casas. A remuneração se dá por peça produzida e as jornadas de trabalho chegam a 15 horas diárias, podendo se estender aos fins de semana. 0 acordo com a empresa que repassa o serviço é apenas verbal, não tendo qualquer garantia de continuidade da relação. Não raro se verifica a atividade de quarteirização, em que uma banca maior, que negocia diretamente com a fábrica, repassa o serviço para outras oficinas, normalmente vizinhas. Nesses casos, o trabalho informal é duplamente explorado, visto que, além do baixo valor pago pela fábrica, a banca terceirizada que media a relação fica com uma parte do que é pago por peça. Ainda existem casos em que há um in- 
termediador que não executa qualquer tipo de atividade produtiva, apenas negocia a relação entre as fábricas e as bancas, se apropriando de parte da remuneração destas.

Também encontramos situações em que o trabalhador domiciliar busca regularizar sua situação, registrando-se como contribuinte autônomo no INSS ou se inscrevendo no programa "Empreendedor Individual", pelo qual profissionais autônomos podem criar uma "Micro Empresa Individual". A jornada e as condições de trabalho, nesses casos, em nada se diferenciam da atividade executada pelo trabalhador informal, em que pese o acesso a alguns benefícios dos quais os últimos estão alijados. Em outras situações, o trabalhador domiciliar pode ser contratado diretamente pelas empresas. Nesses casos, mantém-se a relação de assalariamento, com a condição de que o trabalhador produza uma quantidade determinada de pares por dia. De acordo com trabalhadores entrevistados, a vantagem dessa forma de trabalho se encontra na maior flexibilização da jornada de trabalho, uma vez que o trabalho domiciliar permite uma maior autonomia em relação à hierarquia fabril, com a conveniência de que os direitos vinculados ao registro em carteira continuam assegurados.

(o trabalho na banca) compensa, assim, se eu faltar. Tenho que levar meu filho no médico, aí eu compenso a noite, em outro dia. Se você faltar numa fábrica, num dia normal, de segunda a quinta, você perde o dia, um domingo ou um feriado. Se você faltar na sexta, você perde o sábado e o domingo. Aqui não. Você pode acordar 8 horas da manhã e trabalhar até um pouquinho mais tarde. Dia de chuva, você tá dentro da sua casa." (Trabalhador de banca domiciliar em Birigui).

De maneira geral, todos esses trabalhadores compartilham a experiência de sobreviver na insegurança provocada pela instabilidade do setor de calçados. 0 que varia são as condições de maior ou menor autonomia (sempre relativa) e as possibilidades de enfrentar os períodos de baixa produção, estando mais ou menos coberto por direitos trabalhistas. A partir dessas considerações, se torna mais preocupante a percepção de que a relação salarial tem gradualmente perdido garantias historicamente conquistadas, voltando a sua condição original de precariedade (LIMA, 2010). 0 processo de terceirização acaba por aplicar um verniz modernizador às práticas de subcontratação surgidas junto com a grande indústria, assim como recupera formas de utilização e organização do trabalho anteriores ao período que permitiu a idealização de uma sociedade salarial nos moldes do chamado Welfare state dos países centrais. Nesse sentido, a terceirização parece articular novas e ve- 
lhas formas de exploração da força de trabalho, em um movimento no qual se torna difícil dissociar processo de terceirização, flexibilização e trabalho precário.

\section{Informalidade e empreendedorismo}

O discurso empreendedor dos anos 1990 se fez presente na indústria de calçados endossando as tentativas de criação do próprio negócio por parte de muitos trabalhadores que foram atingidos pelo desemprego, consequência do aumento da terceirização e da migração industrial. Foi nesse período que os polos de Franca, Birigui e Jaú assistiram ao crescimento radical do número de bancas prestadoras de serviço, a maioria na condição de informalidade. Com a ressalva de que não podemos falar em processo de precarização do trabalho na indústria de Jaú, tal como ocorreu nos outros polos, visto que o polo de Jaú só vai se consolidar durante a década de 1990, já inserido no modelo da produção flexível, a despeito da produção de calçados na cidade remontar à década de 1950.

Almeida (2008), ao estudar o trabalho informal na indústria de Franca, percebe que a criação de uma microempresa ou, até mesmo, o trabalho domiciliar são ocupações valorizadas pelos trabalhadores, ainda que esses empreendimentos tenham vida curta e estabeleçam contratos verbais instáveis com as fábricas. 0 motivo atribuído para essa tendência se relaciona com os baixos salários pagos no setor, mesmo nos empregos formais, e com a fragilidade dos vínculos empregatícios, vide a alta taxa de rotatividade na indústria local. A partir dessa conjuntura instável e precária, a pesquisadora conclui que os trabalhadores se sentem impelidos a buscarem a condição de "patrão de si mesmo".

A disseminação da ideologia do empreendedorismo, com a proposição de que a sobrevivência no mercado de trabalho depende, acima de tudo, do esforço individual, traz consigo a responsabilização do trabalhador por sua própria empregabilidade. Este se torna um empresário de sua própria força de trabalho, devendo aperfeiçoá-la para que o mercado possa utilizar suas capacidades. A pessoa se torna uma empresa e a auto-exploração substitui a exploração, rendendo lucros às grandes empresas, clientes do auto-empresario (GoRz, 2005). A informalidade também é ressignificada nesse processo, visto que o trabalhador informal, em vez de um excluído do mercado, passa a ser percebido como um "empreendedor por necessidade", cuja sobrevivência do próprio negócio depende da sua predisposição em inovar, assumir riscos e trabalhar duro (LIMA, 2010). 
A ideologia do empreendedorismo tende a interpretar o trabalho precário nas bancas de calçados como uma possibilidade de libertação do espírito empreendedor dos trabalhadores. Podemos conferir exemplo dessa perspectiva através de um estudo realizado pelo SEBRAE em Jaú, no qual a organização aponta a "necessidade de criar uma 'consciência de empresário' para os donos de banca, pois muitos deles continuam se enxergando como 'sendo empregado da empresa que lhe dá serviço'” (SEBRAE, 2003, p. 214). Vale ressaltar que o SEBRAE trabalha com duas categorias principais: "empresário", que já possui um empreendimento formal em atividade, e "empreendedor", pessoa que pretende iniciar um negócio ou desenvolve uma atividade que ainda carece de regularização (Melo, 2008). Dessa forma, o trabalhador informal é visto como um empreendedor que pode vir a se tornar um empresário, desde que deixe de se perceber como um empregado. Fator que tende a dar legitimidade a uma condição precária na informalidade não mais vista como transitória, mas constituinte das formas flexíveis de estruturação do trabalho.

Contudo, o estudo realizado nos mostrou as complicações de se associar o trabalhador informal da indústria de calçados com a figura do microempreendedor independente. A fragilidade dos contratos, isso quando eles existem, deixa o trabalhador a mercê da demanda instável das fábricas. A relativa autonomia proporcionada pelo trabalho nas bancas se resume à flexibilidade da jornada de trabalho. Assim, são muito raros os casos de trabalhadores/proprietários de bancas que se veem como empresários em potencial. De fato, encontramos situações em que o discurso do empreendedorismo aparece dando contornos modernos ao trabalho nas bancas, como no caso de um ex-funcionário fabril que montou uma oficina domiciliar em Franca, se inscreveu no programa "Empreendedor Individual" e planejar abrir uma pequena fábrica no próximo ano. Na pesquisa em Franca também entramos em contato com casos em que discurso semelhante aparece:

banca dá certo com quem não tem problema em trabalhar fora do horário. No começo é difícil pra todo mundo, mas tem que ser sério e bom de trabalho. Comecei trabalhando em casa com a minha mulher, agora to bem. Tem que ter visão. [...] Agora to até pensando em alugar um espaço maior pra poder crescer (Milton - proprietário de banca em Franca).

O discurso empreendedor justifica, por exemplo, o trabalho intenso e a ausência de lazer lançando mão do imperativo da determinação e do trabalho duro como condição para o sucesso do empreendimento. A autonomia, nessa condição de 
"patrão de si mesmo", aparece como contrapartida compensatória à necessidade de se realizar longas jornadas de trabalho e à instabilidade causada pela ausência de direitos. Todavia, em todos os casos analisados, os trabalhadores atribuíam a motivação para criar a própria oficina à precariedade que se estende também ao trabalho formal, com a instabilidade que é inerente ao setor de calçados e os baixos salários pagos pelas empresas. Os valores empresariais são incorporados até certo ponto, a "subordinação consentida" não impede que o trabalhador perceba a precarização da vida (LimA, 2010).

Outro ponto que merece destaque é a diferença na percepção do trabalho domiciliar entre homens e mulheres. Com a pesquisa de campo, percebemos que quando executado pelo homem, o trabalho na oficina tende a se constituir na principal fonte da renda familiar. Essa situação se justifica pela legitimação da construção social do homem como o provedor da família. Quando realizado pela mulher, a renda da banca aparece como complementação de renda, mesmo quando representa a maior parte do orçamento familiar. Disso podemos inferir que o discurso empreendedor aparece com maior força no trabalho informal no setor calçadista juntamente com o crescimento da presença masculina nessas ocupações, resultado do processo de reestruturação produtiva do fim da década de 80 . Na perspectiva feminina do trabalho domiciliar nas bancas de calçado, a maior margem de liberdade proporcionada pela atividade não é exaltada como a condição de "trabalho sem patrão", mas sim valorizada como possibilidade de equalizar trabalho e cuidado da casa e dos filhos, como verificado em todos os casos pesquisados.

\section{Considerações finais}

A partir dos resultados da pesquisa, pode-se perceber que o movimento em direção ao trabalho informal e domiciliar na indústria de calçados é menos resultado da incorporação de uma ideologia do empreendedorismo do que motivado por um senso prático que busca lidar com as necessidades do cotidiano sem abrir mão da renda proporcionada pela atividade produtiva, além de haver a percepção da precariedade e instabilidade instaladas no próprio trabalho formal. 0 fato é que, concretamente, o trabalho terceirizado, especialmente na condição de informalidade, é muito vantajoso para as empresas, na medida em que permite maior flexibilização da produção e redução de custos com o trabalho vivo. Essa constatação permite reflexões que enxergam na precariedade do mercado de trabalho uma estratégia de 
dominação capitalista, na medida em que a articulação entre força e consentimento se constitui em instrumento do capital para a efetivação do padrão de acumulação, em que a força se materializa na imposição de condições de trabalho precárias numa conjuntura onde o desemprego aparece como uma ameaça constante (DRUCK, 2011).

Com a pesquisa, percebemos que os trabalhadores ainda desejam a condição salarial, mas não na forma como ela têm se apresentado nas últimas décadas. 0 trabalhador almeja um emprego seguro cujas condições de trabalho sejam dignas, artigo cada vez mais raro. A "cultura do assalariamento" ainda está bastante presente entre os trabalhadores, representando um obstáculo à incorporação dos valores do auto-empreendimento (LIMA, 2010). A condição de vulnerabilidade na qual o trabalhador informal está inserido é percebida e, geralmente, verbalizada por ele mesmo. Invariavelmente, os empreendimentos informais visitados são fruto de um "empreendedorismo por necessidade", cujo fundamento está na falta de opções frente às condições do mercado de trabalho. Não queremos dizer com isso que o trabalhador informal que lança mão do discurso empreendedor acredita ter um maior leque de possibilidades, uma vez que junto ao discurso otimista pronunciado por esses agentes é manifestada a percepção das adversidades, limites e riscos inerentes à conjuntura atual do mercado de trabalho. Queremos acentuar que um olhar externo sobre a informalidade tende a enxergar inclinações empreendedoras em muitas situações distintas, principalmente no que se refere à possibilidade de ascensão econômica. Contudo, ressignificar informalidade e trabalho precário sob o rótulo de empreendedorismo é corroborar com a ideia de que o trabalhador pobre se dispõe a correr riscos, ignorando o processo de precarização social do trabalho inserido na dinâmica do capitalismo flexível.

\section{Referências}

AlmeidA, M. S. (2010). "A terceirização do calçado em Franca e o desmonte do contrato formal de trabalho". ORG \& DEMO, Marília, v. 11, n. 2, p. 75-92.

. (2008). A miríade de atores produtivos na terceirização do calçado em Franca. Dissertação de Mestrado, São Paulo, FFLCH-USP.

CASTEL, R. (1998). As metamorfoses da questão social. Uma crônica do salário. Petrópolis, Vozes.

CASTELLS, M. (1999). A sociedade em rede. Rio de Janeiro, Paz e Terra. 
DRUCK, G. (2011). “Trabalho, precarização e resistências: novos e velhos desafios?”. Caderno CRH, Salvador, n. 1, v. 24, p. 35-55.

Gorz, A. (2005). O imaterial: conhecimento, valor e capital. São Paulo, Annablume.

LiMA, J. C. (2002). As artimanhas da flexibilização: o trabalho em cooperativas de produção industrial. São Paulo, Terceira Margem.

. (2009). "A terceirização e seus espaços: os territórios da precariedade - a experiência da indústria de confecção e calçados". In: DAU, D.; RoDRIGUES, I.; CoNCEIÇÃo, J. (Org.). Terceirização no Brasil: do discurso da inovação à precarização do trabalho (atualização e perspectivas). São Paulo, Annablume, v. 1, p. 69-84.

. (2010). "Participação, empreendedorismo e autogestão: uma nova cultura do trabalho?". Sociologias, Porto Alegre, v. 12, p. 158-198.

MELo, N. M. (2008). SEBRAE e empreendedorismo: origem e desenvolvimento. Dissertação de Mestrado, São Carlos, UFSCar.

Navarro, V. L. (2006). Trabalho e trabalhadores do calçado. São Paulo, Expressão Popular.

Sebrae (2003). Estudo da Atividade Empresarial: Setor Calçadista - Fabricação de Calçados Femininos. Jaú, São Paulo.

Recebido em dezembro/2012

Aprovado em janeiro/2013 